\title{
LA INVESTIDURA DE LOS PRESIDENTES AUTONÓMICOS Y PRIMARIAS EN LOS PARTIDOS POLÍTICOS: FORTALECIMIENTO DEL PRESIDENCIALISMO PARLAMENTARIO AUTONÓMICO
}

\section{THE INVESTITURE OF THE AUTONOMICS PRESIDENTS AND PRIMARIES IN POLITICAL PARTIES: STRENGTHENING OF THE PARLIAMENTARY PRESIDENTIALISM IN THE AUTONOMUS COMUNITIES.}

\author{
Andrés Iván Dueñas Castrillo*
}

Recibido: 22/05/2017

Aceptado: $12 / 06 / 2017$

\begin{abstract}
SUMARIO: I.- INTRODUCCIÓN. II.- LA INVESTIDURA DE LOS PRESIDENTES AUTONÓMICOS. 1.- LA STC 225/1998 Y EL POSIBLE CIERRE DE LA ORGANIZACIÓN INSTITUCIONAL AUTONÓMICA. 2.- LA INVESTIDURA. El PAPEL DE LA PRESIDENCIA DE LAS CÁMARAS Y DE LOS PARTIDOS POLÍTICOS. 3.EXPIRACIÓN DEL PLAZO PARA NOMBRAR PRESIDENTE. III.- PRIMARIAS Y AFECCIÓN A LA INVESTIDURA EN LAS COMUNIDADES AUTÓNOMAS. IV.- CONCLUSIONES. V.BIBLIOGRAFÍA.
\end{abstract}

SUMMARY: I.- INTRODUCTION. II.- THE INVESTITURE OF AUTONOMIC PRESIDENTS. 1.- THE STC 225/1998 AND THE POSSIBLE CLOSURE OF THE AUTONOMOUS INSTITUTIONAL ORGANIZATION. 2.- THE

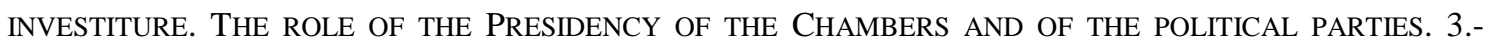
EXPIRY OF THE TERM TO APPOINT PRESIDENT. III.- PRIMARY AND INVESTITURE AFFECTION IN THE AUTONOMOUS COMMUNITIES. IV.- CONCLUSIONS. V.- BIBLIOGRAPHY.

Resumen: Las últimas elecciones autonómicas y generales de 2015 y 2016 han traído consigo un nuevo escenario partidista al que estábamos desacostumbrados tanto en el ámbito autonómico como en el estatal. Ello ha conllevado mayores dificultades a la hora de investir a los Presidentes autonómicos y al propio Presidente del Gobierno. A su vez, las nuevas propuestas en materia de regeneración democrática, como las primarias en los partidos políticos, pueden ser fórmulas novedosas que mejoren la relación entre representantes y representados, pero que desfiguren la forma de gobierno parlamentaria imperante en nuestro sistema. Este artículo se adentra en dicha cuestión, junto con las diferencias entre la manera de investir a los Presidentes autonómicos en las Comunidades Autónomas.

\footnotetext{
* Profesor asociado de Derecho Constitucional de la Universidad de Valladolid y asesor jurídico en las Cortes de Castilla y León. andres.d.castrillo@gmail.com / andresivan.duenas@uva.es Número ORCID: 000-0001-8571-0922
} 
Palabras clave: Investidura, Parlamento, Presidente, democracia, primarias.

Abstract: Last Autonomous and State 2015 and 2016 elections have brought a new partisan scene which we were not used to both in the autonomous and state area. This has carried major difficulties when it has come the moment to invest the autonomous Presidents and the own Prime Minister. At the same time, new democratic regeneration proposals, as primary elections inside the politic parties, can be new formulae that improve the relations between representative and represented, but which disfigure the parliamentary form of Government prevailing in our system. This article delves into this question, along with the differences between the way to empower the regional Presidents in the autonomous communities.

Keywords: Investiture, Parliament, President, democracy, primaries.

\section{I.- INTRODUCCIÓN ${ }^{1}$}

Las elecciones autonómicas de mayo de 2015, junto con las generales de diciembre de 2015 y de junio de 2016, propiciaron que el sistema de partidos se modificara en las Comunidades Autónomas y en el ámbito estatal. Ello ha conllevado que la investidura de los Presidentes autonómicos fuera más dificultosa en algunas regiones españolas y también en el ámbito estatal.

Aunque la mayoría de Comunidades Autónomas optaron por un modelo de investidura prácticamente análogo al dispuesto en el artículo 99 CE para el Presidente del Gobierno de España, no todas lo eligieron. Unas, al desarrollar dicha cuestión, prefirieron dar más importancia a los Grupos Parlamentarios que a la Presidencia de los Parlamentos y otras, incluso, optaron por un sistema más novedoso en el caso de que no se llegase a un acuerdo de investidura en el plazo previsto, a través de fórmulas de parlamentarismo negativo.

Actualmente, nos encontramos, además, con propuestas que están siendo debatidas en algunos Parlamentos Autonómicos, que pretenden introducir en las Leyes Electorales la obligatoriedad para los partidos de elegir a sus candidatos a la Presidencia

\footnotetext{
${ }^{1}$ El presente estudio se realiza en el marco del Proyecto de Investigación DER2016-75993-P, sobre “España ante Europa: retos nacionales en materia de derechos humanos”, que se desarrolla entre el 30 de diciembre de 2016 y el 29 de diciembre 2020.

El artículo está dedicado a los integrantes del Grupo Parlamentario Podemos Castilla y León, que me han permitido conocer de primera mano el funcionamiento de un Parlamento autonómico y asistir al último debate de investidura del Presidente de la Junta de Castilla y León.
} 
por primarias, con los problemas que ello conlleva en relación con la limitación de la autoorganización de los propios partidos, el conflicto con las competencias del Estado y la posible contradicción con la forma parlamentaria de Gobierno.

En estas líneas se pretende investigar, en primer lugar, cuál es el papel actual de los Parlamentos autonómicos en la investidura de los Presidentes de las Comunidades Autónomas; para pasar a analizar, en segundo término, las posibilidades de regulación legal de las primarias en los partidos políticos y su posible afectación a la forma de gobierno de las Comunidades Autónomas.

\section{II.- LA INVESTIDURA DE LOS PRESIDENTES AUTONÓMICOS.}

\section{1.- La STC 225/1998 y el posible cierre de la organización institucional autonómica}

Según ARAGÓN REYES, de los arts. 147.2 c) y 148.1.1 ${ }^{\text {a }}$ CE se desprende que no cabe Comunidad Autónoma sin instituciones de autogobierno, pues no cabe Comunidad Autónoma sin Estatuto y tales instituciones son contenido necesario de éste. De ellos también se puede concluir que el establecimiento, denominación y rasgos estructurales básicos de esas instituciones constituye una materia reservada al Estatuto; quedando, pues, reservado al principio dispositivo, la calificación (política o administrativa), determinación (número y clase) y composición y funciones de los órganos de autogobierno. Sin embargo, este principio dispositivo se ve limitado por ciertas normas constitucionales, como el artículo $152.1 \mathrm{CE}^{2}$, indicado anteriormente.

El resto de Comunidades Autónomas optó por acogerse a ese modelo de forma mayoritaria desde el principio, suponiendo una semejanza y similitud de los diferentes sistemas territoriales entre sí y "una recepción acrítica de los modelos organizativos tradicionales”3. Actualmente, se sigue hablando de un excesivo mimetismo de los Parlamentos Autonómicos y la doctrina está de acuerdo en que "formalmente, las

\footnotetext{
${ }^{2}$ ARAGÓN REYES, M., Estudios de Derecho Constitucional, CEPC, $3^{a}$ edición, Madrid, 2013, pp. 847849.

${ }^{3}$ PENDÁS GARCÍA, B., “Gobierno y forma de gobierno de las Comunidades Autónomas. Reflexiones sobre el dogma de la homogeneidad y sus límites”, en Documentación Administrativa, no 215, julioseptiembre 1988, p. 85.
} 
Comunidades Autónomas reproducen el modelo estatal”4 y también se puede afirmar que “en el desarrollo institucional autonómico convergen dos fuerzas en tensión constante: la tentación por la reproducción mimética al modelo estatal y un constante anhelo por expresar de forma manifiesta la peculiaridad territorial” 5 .

Sin embargo, la STC 225/1998 parece decir lo contrario de la anterior afirmación. El Defensor del Pueblo interpuso un recurso de inconstitucionalidad en relación con el párrafo segundo de la disposición transitoria primera de la Ley Orgánica 4/1996, de 30 de diciembre, de reforma de la Ley Orgánica 10/1992, de 10 de agosto, del Estatuto de Autonomía de Canarias, que establecía un régimen transitorio regulatorio de la composición electoral del Parlamento de Canarias cuyo contenido podía infringir el principio de representación proporcional establecido en el artículo $152.1 \mathrm{CE}$, al introducir un elemento característico del sistema mayoritario, como es la inclusión de la lista más votada en la circunscripción en detrimento del principio de representación territorial; o la elevación de las barreras electorales del 3 al 6 por ciento en el ámbito de la Comunidad Autónoma y del 20 al 30 por cierto en cada circunscripción insular, según el recurrente.

La Comunidad Autónoma de Canarias, en su día, no se constituyó por el procedimiento del artículo 151 CE por lo que, siguiendo a ARAGÓN REYES, no debería aplicarse a ésta lo dispuesto en el artículo 152.1 CE. Sin embargo, es sorprendente la argumentación del Tribunal Constitucional al respecto, que lo niega en su F.J. 6”: “de conformidad con el principio dispositivo que informó el acceso a la autonomía política de las nacionalidades y regiones (artículo 2 CE), las Comunidades Autónomas constituidas por el cauce del artículo 143 CE podían contar o no según sus Estatutos con una Asamblea Legislativa como la que prevé, para otros casos, el artículo 152.1 CE. El Estatuto de Autonomía de Canarias optó por dotar a esa Comunidad Autónoma de una Asamblea Legislativa como la prevista en el artículo 152.1 CE para

\footnotetext{
4 TUDELA ARANDA, J., “El Parlamento autonómico y la calidad de la democracia”, en TUDELA ARANDA, J. (ed.): Los Parlamentos autonómicos en tiempos de crisis, Fundación Manuel Giménez Abad, Zaragoza, 2015, p. 27.

${ }^{5}$ DURÁN ALBA, J.F., "El cierre del sistema institucional castellano y leonés tras la última reforma estatutaria: semejanzas y diferencias con el modelo estatal”, en Revista Jurídica de Castilla y León, $\mathrm{n}^{\circ}$ extra 1, 2004, p. 178.
} 
aquellas Comunidades que accedieron a la autonomía política por la vía regulada en el artículo $151 \mathrm{CE}$, por lo que dicha Asamblea habrá de ser elegida con sujeción al mandato de representación proporcional; en el particular caso de la Comunidad Autónoma de Canarias es de apreciar la progresiva asimilación de competencias en relación con las Comunidades Autónomas del artículo 151 CE operada mediante la Ley Orgánica 11/1982, de 10 de agosto, de Transferencias Complementarias a Canarias, proceso de acercamiento que también es lógica que tenga su trasunto en el plano orgánico e institucional. Ninguna duda existe, pues, sobre la utilización del artículo 152.1 CE como canon de constitucionalidad para el enjuiciamiento del precepto estatutario impugnado".

Lo que hace aquí el Tribunal Constitucional, por tanto, es cerrar el modelo autonómico en su plano institucional: ya no existe principio dispositivo en este ámbito, ni tan siquiera para las Comunidades Autónomas que no se constituyeron por la vía del artículo 151 CE. Se hace una interpretación extensiva del artículo 152.1 CE mediante la cual se establece que, aquellas Comunidades Autónomas que hubieran optado por seguir un modelo basado en la autonomía política, han de respetar el contenido del artículo 152.1 CE, sin que puedan elegir su forma de autogobierno. Siguiendo a DURÁN ALBA, a la luz de esta sentencia se ha extendido “el modelo institucional del artículo 152 CE a todas las Comunidades Autónomas, convirtiendo el precepto en un canon de la organización institucional autonómica limitador del principio dispositivo” ${ }^{\text {. }}$

Esta línea mantenida por el Tribunal Constitucional, en un primer momento, fue seguida por algún autor, que dedujo del artículo 152.1 CE la existencia de una línea divisoria entre las Comunidades "de verdadera sustancia política” y aquellas que "se mueven solamente en el nivel secundario de la simple centralización administrativa”" Por tanto, una vez todas las Comunidades Autónomas han adquirido poder legislativo, lo lógico es que el artículo 152.1 CE se haga extensible a todas ellas.

\footnotetext{
${ }^{6}$ DURÁN ALBA, J. F., "Las instituciones de autogobierno y otros órganos autonómicos ante el proceso de reforma estatutaria", en La Reforma de los Estatutos de Autonomía, Junta de Castilla y León-Revista Jurídica de Castilla y León, 2005, p. 368.

${ }^{7}$ RAMÓN FERNÁNDEZ, T., "La organización territorial del Estado y la Administración Pública en la nueva Constitución”, en Lecturas sobre la Constitución española, vol. 1, UNED, Madrid, 1978, p. 351.
} 
El voto particular formulado por el magistrado CRUZ VILLALÓN en la STC 225/1998 aduce lo contrario, manteniendo que el artículo 152.1 CE

“comienza delimitando su ámbito de proyección a los solos Estatutos aprobados por el procedimiento a que se refiere el artículo anterior, lo que nunca ha sido el caso de Canarias”. Lo que ha hecho el Estatuto de esta Comunidad Autónoma ha sido optar “por dotar a la Comunidad Autónoma por una Asamblea como la que se prevé en el artículo 152.1 CE. Desde luego, ha optado por una Asamblea con poderes legislativos pero, en primer lugar, ha optado, lo que debería llevar a pensar que del mismo modo, aunque sea en línea de principio, podría dejar de optar; y, sobre todo, el haber optado por una Asamblea Legislativa en el marco de lo previsto en el artículo 143 CE no convierte a ésta automáticamente y sin más en la Asamblea Legislativa del $151 \mathrm{CE}$, con todas sus exigencias.

La realidad, a partir de la Constitución que tenemos, es que el Estatuto de Autonomía de Canarias no está vinculado por el artículo 152.1 CE y, en concreto, por el mandato, ahí contenido, de establecer un sistema de representación proporcional para la Asamblea Legislativa en dicho artículo prevista $(\ldots)$ ”.

La mayoría de la doctrina es conforme al voto particular del magistrado CRUZ VILLALÓN, hasta tal punto de que se podría afirmar que la posición del Tribunal Constitucional constituye “una extensión analógica que, por otra parte, vulneraría el principio dispositivo, clave en el diseño de nuestro Estado Autonómico"8. A mayor abundamiento, como afirmaba SOLÉ TURA, esta diferenciación en la Constitución entre el modelo institucional de las Comunidades Autónomas tiene como explicación que “en los Estatutos tramitados

\footnotetext{
${ }^{8}$ GIMÉNEZ SÁNCHEZ, I.M., "La forma de gobierno autonómica tras las recientes reformas de los Estatutos de Autonomía”, en Asamblea: Revista Parlamentaria de la Asamblea de Madrid, núm. 22, junio 2010, p. 141.
} 
por la vía del artículo 151 CE las Cortes no tienen la responsabilidad total y única del procedimiento de elaboración y aprobación”9 ${ }^{\text {. }}$

En este mismo sentido, aunque los acuerdos políticos entre la UCD y el PSOE de 1982 condujeran hacia una homogeneización del sistema institucional autonómico, nada obstaba para que las Comunidades Autónomas no vinculadas por el artículo 152.1 optaran por otro modelo distinto. Ya sucedió con las Comunidades Autónomas que aprobaron sus respectivos Estatutos durante la II República, las cuales tuvieron modelos diferenciados. Por ejemplo, el Estatuto gallego preveía un sistema presidencialista, en el cual el Presidente sería elegido de manera directa mediante sufragio universal ${ }^{10}$. Sin embargo, esta sentencia parece concluir lo contrario.

\section{2.- La investidura. El papel de la Presidencia de las Cámaras y de los partidos políticos}

Aunque posteriormente se hablará someramente sobre la forma de gobierno de las Comunidades Autónomas, es necesario indicar que la regulación del procedimiento de nombramiento del Presidente "no es una cuestión baladí o de mera técnica organizativa, sino que expresa y asume el significado esencial de la forma de gobierno parlamentaria: la expresión de voluntad del Parlamento como presupuesto formalmente determinante del acceso al cargo de Presidente y la instauración ab initio de un vínculo fiduciario institucional que sirve de título para el ejercicio por parte de éste de la función de gobierno"11.

La mayoría de Comunidades Autónomas tomó como referencia el artículo 99 CE para la investidura de sus Presidentes, pero no todas optaron inicialmente por el mismo patrón. En el modelo estatal, el Presidente del Congreso "se limita al refrendo de la propuesta regia y a la de ser mero portavoz de la misma”, y en el ámbito autonómico, “en unos Estatutos de Autonomía y Leyes autonómicas reguladoras del Gobierno se

\footnotetext{
${ }^{9}$ SOLÉ TURA, J., “Las Comunidades Autónomas como sistemas semipresidenciales”, en El Gobierno en la Constitución Española y en los Estatutos de Autonomía, Diputación de Barcelona, 1985, p. 294.

${ }^{10}$ VILAS NOGUEIRA, X., O Estatuto Galego, Edicións do Rueiro, A Coruña, 1977, pp. 261 y ss.

${ }^{11}$ REVENGA SÁNCHEZ, M.: "Notas sobre el procedimiento de designación del Presidente del órgano colegiado ejecutivo en las Comunidades Autónomas”, en Revista Vasca de Administración Pública, $\mathrm{n}^{\circ}$ 14, 1986, p. 92.
} 
otorga ese papel al Presidente del Parlamento; en otros a los grupos parlamentarios o a las fuerzas políticas con representación parlamentaria”12. SÁNCHEZ AGESTA, primariamente, interpretó que el del Rey es “un acto discrecional, aunque, como es natural, está condicionado por estas consultas previas y por la proporción de los grupos parlamentarios en el Congreso" ${ }^{\prime 3}$. Sin embargo, parece no tener en cuenta la previsión del artículo 99.1 CE del necesario refrendo del Presidente del Congreso en la propuesta regia. Aunque es cierto que hay dos posturas encontradas en la doctrina, entre las que entienden que dicho refrendo es puramente certificante o de legalidad y las que defienden que también es de oportunidad política, me inclino por aquellas que mantienen que por la expresión refrendo de la legalidad constitucional no se ha de entender "únicamente la comprobación de los requisitos formales, sino la adecuación de la propuesta a la ratio del artículo 99 CE. En este sentido, y de manera excepcional, el Presidente del Congreso debería negar el refrendo a una propuesta de candidato que de forma manifiesta resultara incompatible con la composición de la Cámara y fuera totalmente inviable derivar de la misma la investidura parlamentaria” ${ }^{14}$. Hay que tener en cuenta, además, que la función última del refrendo es "la traslación de responsabilidad desde el monarca hasta el sujeto que refrenda, en consonancia con la inviolabilidad de la persona del rey y su no sujeción a responsabilidad” ${ }^{15}$. En este mismo sentido, SOLOZÁBAL ECHAVARRÍA mantiene que la intervención del Presidente del Congreso "refrenda la regularidad constitucional del rey, que asume su

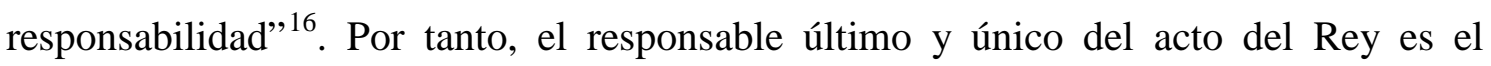
Presidente del Congreso, "tanto de la propuesta como de la fase anterior, la de las consultas regias con los representantes de las fuerzas parlamentarias” ${ }^{17}$, al igual que el

\footnotetext{
12 BASTIDA FREIJEDO, F.J., "Investidura de los Presidentes Autonómicos y parlamentarismo negativo", en Revista Jurídica de Asturias, n 17, 1993, p. 12.

${ }^{13}$ SÁNCHEZ AGESTA, L, Sistema político de la Constitución española de 1978, EDERSA, Madrid, 1987, p. 271.

${ }^{14}$ VINTRÓ CASTELLS, J., La investidura parlamentaria del Gobierno: perspectiva comparada y Constitución española, Congreso de los Diputados, Madrid, 2006, p. 291.

${ }^{15}$ REVENGA SÁNCHEZ, M., "La funcionalidad del artículo 99 de la Constitución ante el caso de un resultado electoral fragmentado: ¿mejorar su aplicación o proponer su reforma?, en Revista Española de Derecho Constitucional, no 109, 2017, p. 106.

${ }^{16}$ SOLOZÁBAL ECHAVARRÍA, J.J., "La problemática constitucional de la formación del Gobierno y la intervención del monarca en nuestro régimen parlamentario", en Revista Española de Derecho Constitucional, $\mathrm{n}^{\circ}$ 109, 2017 p. 53.

${ }^{17}$ TORRES DEL MORAL, A., Principios de Derecho Constitucional español, Madrid, 2004, p. 58.
} 
encargado de proponer al candidato a presidir las Comunidades Autónomas, en casi todas ellas, es el Presidente de la Asamblea. Dicho de otra manera, "el refrendo del Presidente del Congreso confirma que éste es el que asume la responsabilidad del acto del Rey, lo que despeja las dudas acerca de las posibilidades discrecionales del Monarca a la hora de proponer un candidato a la Presidencia” ${ }^{18}$. De no ser así, se otorgaría una de las funciones políticas más importantes al Rey, algo inconcebible en cualquier Monarquía Parlamentaria, ya que la figura del monarca acabaría adquiriendo responsabilidad y pondría, por tanto, en riesgo a la propia monarquía ${ }^{19}$.

La falta de una figura como el Rey que sea proponente de candidatos en las Comunidades Autónomas ha conllevado una regulación no uniforme entre ellas ${ }^{20}$. Fueron siete las Comunidades Autónomas que establecieron inicialmente un modelo diferenciado: Asturias, Comunidad Valenciana, Extremadura, País Vasco, Andalucía, Castilla-La Mancha y Navarra. La única de estas Comunidades Autónomas que modificó su procedimiento de investidura y lo acercó al establecido en las demás fue, precisamente, esta última: Navarra. Sin embargo, su sistema, junto con el andaluz y el castellano-manchego, era el más singular de los citados, por lo que es obligatorio detenerse a analizarlo, aunque sea de manera breve, para estudiar posteriormente los demás.

La Ley Orgánica 13/1982, de 10 de agosto, de Amejoramiento del Fuero de Navarra (LORAFNA), establecía, hasta la reforma realizada por la Ley Orgánica 1/2001, de 26 de marzo, que, de no conseguirse la mayoría requerida (mayoría absoluta en primera votación y mayoría simple en segunda y sucesivas votaciones) en el plazo de dos meses, sería designado el candidato del partido que tuviera mayor número de escaños (artículo 29.3). El apartado segundo del citado artículo establecía que quien realizaba la propuesta de candidato era el Presidente de la Cámara. Esta no era una

\footnotetext{
${ }^{18}$ ÁLVAREZ VÉLEZ, M. I., "La investidura del Presidente del Gobierno y las similitudes y diferencias de las investiduras de los Presidentes Ejecutivos autonómicos”, en Revista General de Derecho Constitucional, n 22, 2016, p. 8.

${ }_{19}$ ARAGÓN REYES, M., "Legislatura fallida e investidura convulsa. Análisis y consecuencias", en Revista Española de Derecho Constitucional, n ${ }^{\circ}$ 109, 2017, p. 20.

${ }^{20}$ BASTIDA FREIJEDO, F.J., "De nuevo sobre el modo de designación de los Presidentes Autonómicos y la forma de gobierno”, en Parlamento y Constitución. Anuario de las Cortes de Castilla-La Mancha, ${ }^{\circ}$ 5, 2001, p. 45.
} 
regulación novedosa, sino que el estatuyente navarro, al igual que el andaluz y el castellano-manchego, tuvo en cuenta la cláusula prevista en el artículo 28 de la Ley 39/1978, de 17 de julio, de elecciones locales, en la que se preveía que si ningún miembro de la Corporación era elegido alcalde por el voto de la mayoría absoluta de sus concejales, se proclamaría de forma automática como tal el concejal que encabezara la lista más votada por los electores de municipio ${ }^{21}$.

Este sistema entra dentro de los considerados como "parlamentarismo negativo". BASTIDA FREIJEDO explica que éste se presenta como un instrumento de racionalización parlamentaria y está inspirado en las monarquías del norte europeo, donde el Primer Ministro nombrado por el rey no tiene que someterse a una votación de investidura (caso de la antigua regulación de la LORAFNA) o el candidato propuesto por el Presidente del Parlamento no obtiene un voto en contra de la mayoría de los miembros de la Cámara ${ }^{22}$, como podría resultar de las votaciones nominales en la investidura. En este caso, al igual que sucede en la trayectoria seguida por la Constitución holandesa, las de las tres Monarquías escandinavas y el Reino Unido, conforme a las cuales se puede formar Gobierno sin precisarse de la previa investidura del Parlamento, "la presunción del favor parlamentario al Gabinete ministerial es iuris tantum, es decir, admite la prueba en contrario del voto de censura” ${ }^{23}$, pero siempre en un momento posterior para entender destruida dicha confianza. De la misma manera, VIDAL MARÍN interpreta que a través de esta cláusula de designación automática "la confianza se entiende otorgada no expresamente, pero sí tácitamente y por obra del propio Estatuto de Autonomía”24, aunque hay autores que mantienen que esta posibilidad de investidura automática carece de sentido en una forma de gobierno parlamentaria $^{25}$. Este sistema tiene como ventaja garantizar el nombramiento de un

\footnotetext{
${ }^{21}$ VIDAL MARÍN, T., "La investidura de los Presidentes Autonómicos: la eliminación de la designación automática. ¿Acierto del legislador?”, en Repertorio Aranzadi del Tribunal Constitucional, nº 15, 2007, p. 10 .

${ }^{22}$ BASTIDA FREIJEDO, F.J., "Investidura de los Presidentes Autonómicos y parlamentarismo negativo", op. cit., p. 28.

${ }^{23}$ ALZAGA VILLAAMIL. O., Comentario sistemático a la Constitución española de 1978, Marcial Pons, $2^{\mathrm{a}}$ ed., Madrid, 2016, p. 482.

${ }^{24}$ VIDAL MARÍN, T., op. cit., p. 12.

${ }^{25}$ BALAGUER CALLEJÓN, M.L., "Derecho de disolución e investidura automática en las Comunidades Autónomas”, en Revista de las Cortes Generales, nº 18, 1989, p. 276.
} 
Presidente del Ejecutivo sin necesidad de disolución del Parlamento, pero como inconveniente la debilidad del posible Gobierno.

El procedimiento de investidura de la antigua LORAFNA ha sido objeto de dos sentencias del Tribunal Constitucional que merece la pena mencionar. La primera de ellas, la STC 16/1984, resuelve el problema del término “candidato”. La LORAFNA establecía que es candidato el propuesto por el Presidente de la Cámara, previa consulta con los Grupos Parlamentarios, teniendo que someter su programa a votación del Pleno de la Cámara. Sin embargo, la Presidencia del Parlamento Foral de Navarra entendió que en el supuesto extraordinario de transcurso del plazo de dos meses, no se requería haber sido previamente candidato ni haber sometido su programa a votación del Pleno. Es decir, esta segunda interpretación supone que "la designación ha de llevarse a cabo por el partido con más escaños en la Cámara, independientemente de que el candidato hubiera concurrido o no a la fase previa de investidura” (F.J. 50). El Tribunal Constitucional valora en este pronunciamiento que, en todo caso, ha de darse la oportunidad a la Asamblea de pronunciarse en un debate de investidura, ya que, de no ser así, "aceptar que la propuesta del Presidente del Parlamento pueda realizarse en favor de un candidato que no haya dado oportunidad alguna a la Asamblea de pronunciarse sobre un programa resultaría así un fraude a la voluntad de la ley” (F.J. $\left.8^{\circ}\right)$. Aunque esta no sea estrictamente la materia de investigación del presente trabajo, es preciso hacer un comentario acerca de dicha afirmación: el procedimiento extraordinario habla del candidato "del” partido con más escaños, siempre que hayan transcurrido dos meses a partir de la primera votación, en cuyo plazo se pueden tramitar otras propuestas de candidato por el Presidente de la Cámara en la forma prevista en el apartado 2 del antiguo artículo 29 de la LORAFNA. Parece, por tanto, al contrario de lo que opina el Tribunal Constitucional, que estaríamos ante un claro ejemplo de parlamentarismo negativo, como he mencionado antes. Este es el modelo previsto en Suecia, consistente en "una presunción de confianza definida en términos negativos, de no hostilidad contra el candidato, salvo que la mayoría de los miembros del Parlamento 
haga explícita su beligerancia”26 (pero siempre en un momento posterior al de investidura). Así, el Presidente de la Cámara no tendría por qué realizar una nueva propuesta, sino que bastaría con que el partido con más número de escaños propusiese a su candidato.

Por su parte, la STC 15/2000 se refirió a la Ley Foral Reguladora del Gobierno y la Administración Foral. Dicho sea de paso que es criticable, por un lado, la falta de seguridad jurídica de algunas Comunidades Autónomas en las cuales el procedimiento de investidura se desarrolla a través de la ley y de los reglamentos de las respectivas Cámaras, además de poder suponer, en segundo lugar, una vulneración de la autonomía parlamentaria de las Cámaras, ya que dicho procedimiento, más allá de los Estatutos de Autonomía, debería ser objeto de desarrollo reglamentario.

La Ley Foral Reguladora del Gobierno y la Administración Foral fue modificada por la Ley Foral 9/1991, que dotó de una nueva redacción al artículo 20.8, el cual pasó de hablar de "partido" a partidos, federaciones de partidos, agrupación o coalición electoral, para el caso extraordinario de investidura automática cuando transcurrido el plazo de dos meses no se hubiera investido a un Presidente. El Tribunal Constitucional, en dicha sentencia, precisamente, se refiere a si dicha modificación contenía una innovación estatutaria, ya que la LORAFANA únicamente hablaba de "partidos". Sin embargo, el Alto Tribunal dictamina que "lo que hace la Ley es adecuar la investidura automática recogida en la LORAFNA al principio democrático y a las previsiones de la LOREG en cuanto a la legitimación para presentar candidaturas electorales. Por eso, la Ley Foral no es una modificación encubierta de la LORAFNA, sino que precisa el significado del término partido contenido en el Estatuto navarro del único modo que es posible" 27 .

Actualmente, la mayoría de Comunidades Autónomas sigue el modelo estatal de investidura del Presidente del artículo 99 CE en sus Estatutos de Autonomía. Algunas

\footnotetext{
${ }^{26}$ BASTIDA FREIJEDO, F.J., "Investidura de los Presidentes Autonómicos y parlamentarismo negativo”, op. cit., p. 30.

${ }^{27}$ ORTEGA SANTIAGO, C., "Sobre la forma de Gobierno de las Comunidades Autónomas y sus fuentes normativas de ordenación”, en Revista Española de Derecho Constitucional, n 59, mayo-agosto 2000, p. 355.
} 
de las que lo hacen, sin embargo, tienen ciertas peculiaridades, como se verá a continuación.

Son cuatro las autonomías que no confieren la potestad de proponer a un candidato a la Presidencia de la Comunidad al Presidente de sus Parlamentos, sino a los Grupos Parlamentarios (País Vasco -artículo 164 del Reglamento del Parlamento del País Vasco- y Comunidad Valenciana -artículo 27 del Estatuto de Autonomía-) o a los diputados individualmente considerados (Asturias -artículo 3 de la Ley 6/1984, de 5 de julio, del Presidente y del Consejo de Gobierno del Principado de Asturias - y Extremadura -artículo 25 del Estatuto de Autonomía-); y otras dos, Andalucía y Castilla-La Mancha, disponen la investidura automática del Presidente una vez expirado el plazo sin que hubiera resultado elegido un candidato por la Asamblea -a las que me referiré posteriormente-. De las que inicialmente establecieron un modelo diferenciado, por tanto, solo Navarra lo ha asimilado al patrón estatal.

En el caso del País Vasco, no se otorga ninguna función al Presidente del Parlamento; de manera distinta, en la Comunidad Valenciana el Presidente es quien finalmente propone al candidato con más apoyo de entre los Grupos Parlamentarios, quien se someterá a la votación del Pleno en la sesión de investidura, pero no puede presentar a alguien que no haya sido propuesto previamente por algún Grupo Parlamentario.

En Asturias, “concierne individualmente a los miembros de la Junta la presentación de los candidatos, siempre que cada propuesta esté avalada por cinco parlamentarios, aunque no pertenezcan a un mismo grupo o partido", es decir, "se trata de un sistema que permite formar Gobierno sin necesidad de acuerdos parlamentarios y que obliga a pactar un candidato a los partidos de la oposición si quieren impedir que el partido ganador, pero de forma relativa, se alce con la Presidencia”28. El Presidente únicamente “proclama”, según el tenor literal del artículo 3 de la Ley 6/1984, a los candidatos propuestos por los diputados. Por su parte, en Extremadura, el Presidente de la Asamblea es quien finalmente propone al candidato, que, previamente, ha de ser

\footnotetext{
${ }^{28}$ ÁLVAREZ VÉLEZ, M. I., op. cit., p. 20.
} 
presentado, al menos, por una cuarta parte de los miembros de la Cámara. En este caso la votación no es nominal.

Sí que es nominal en el País Vasco y Asturias, por lo que se asegura, así, que será investido uno de los candidatos presentados, a no ser que se dé un empate entre alguno de ellos.

En las demás Comunidades Autónomas, como sucede en el ámbito estatal, la función del Presidente de la Cámara se ha visto como una labor de arbitraje ${ }^{29}$, como órgano de “equilibrio y moderación de la Cámara” ${ }^{30}$, aunque también se puede mencionar alguna peculiaridad en el procedimiento. Por ejemplo, el artículo 48.2 del Estatuto de Autonomía de Aragón obliga al Presidente de la Cámara a que, en caso de que el primer candidato a la investidura no obtuviese el respaldo correspondiente, realice nuevas propuestas mediando entre ellas un plazo de 10 días. Ello conlleva que el Presidente no es totalmente libre a la hora de convocar una nueva sesión de investidura (si lo es para la primera, ya que no se establece un plazo desde el nombramiento del candidato a la Presidencia de Aragón para convocar dicha sesión de investidura), sino que, obligatoriamente, ha de convocar una nueva sesión en esos plazos de diez días. Ello otorga la ventaja de dar la posibilidad a la Cámara de un nuevo pronunciamiento, pero podría darse el caso de no retorno porque no existiesen nuevos candidatos a proponer.

\section{3.- Expiración del plazo para nombrar Presidente}

La mayor diferencia que podemos encontrar en los procedimientos de investidura autonómicos, en comparación con el estatal, es que muchas Comunidades Autónomas regulan un plazo obligatorio, en primer lugar, para que se realice la propuesta de candidato y, en segundo lugar, para que el Presidente de la Cámara convoque la sesión de investidura.

\footnotetext{
${ }^{29}$ REVENGA SÁNCHEZ, M.: "Notas sobre el procedimiento de designación del Presidente del órgano colegiado ejecutivo en las Comunidades Autónomas”, op. cit., p. 96.

${ }^{30}$ BASTIDA FREIJEDO, F.J., "De nuevo sobre el modo de designación de los Presidentes Autonómicos y la forma de gobierno", op. cit., p. 45.
} 
En el ámbito estatal, el Rey no está sometido a plazo para proponer al candidato a la Presidencia del Gobierno, "por lo que el momento de la propuesta del candidato queda a criterio del Monarca, que dispondrá de un tiempo razonable en función de la composición de la Cámara y los acuerdos políticos que pudieran adoptarse”31.

Del análisis antes realizado sobre la figura del Presidente del Congreso cabe afirmar que este es el verdadero mediador en la investidura del Presidente del Gobierno $^{32}$. Por tanto, es lógico que cuente con "un margen discrecional muy notable" 33 , pero, en todo caso, no debería ser "función del Presidente del Congreso convocar en función de que el candidato propuesto haya conseguido los apoyos necesarios, pues esto significaría otorgarle un papel que no es el que le corresponde» ${ }^{34}$, sino que se ha de fijar "atendiendo a la conveniencia del candidato, pudiendo serle de utilidad esa flexibilidad temporal para poder elaborar sin apreturas de tiempo su discurso programático y para buscar los más amplios apoyos políticos al mismo”35. A juicio de ÁLVAREZ VÉLEZ, el Presidente debe convocar "el Pleno de investidura con rapidez, para evitar el seguir con un Presidente del Gobierno en funciones, y no cuando el candidato consiga los acuerdos”36. Aunque el sistema electoral del Congreso de los Diputados “se diseñó en la Transición con la intención inequívoca de favorecer la concentración de la representación, para evitar la excesiva fragmentación del Parlamento y propiciar, de este modo, la estabilidad gubernamental”37, los últimos resultados electorales en las elecciones generales de 2015 y 2016 trajeron consigo un Congreso de los Diputados mucho más fragmentado de lo que la tradición parlamentaria española estaba acostumbrada desde la promulgación de la Constitución de 1978. Como consecuencia de ello, la sesión de investidura celebrada a finales de agosto del año pasado tras las elecciones generales del 26 de junio de 2016, no fue convocada por la

\footnotetext{
${ }^{31}$ ÁLVAREZ VÉLEZ, M. I., op. cit., p. 6.

${ }^{32}$ ARAGÓN REYES, M., "Legislatura fallida e investidura convulsa. Análisis y consecuencias”, op. cit., p. 23.

33 DELGADO RAMOS, D., "Breves notas sobre una cuestión controvertida: ¿es posible acortar los plazos para la investidura del candidato a Presidente del Gobierno?”, en Asamblea: revista parlamentaria de la Asamblea de Madrid, n 26, 2012, p. 213.

${ }^{34}$ ÁLVAREZ VÉLEZ, M. I., op. cit., p. 9.

${ }^{35}$ VINTRÓ CASTELLS, J., op. cit., p. 292.

${ }^{36}$ ÁLVAREZ VELEZ, op. cit., p. 10.

37 SÁNCHEZ MUÑOZ, O., "El fin (momentáneo) del bipartidismo en España: análisis de los resultados electorales de 2015 y 2016”, en Revista Española de Derecho Constitucional, nº 109, 2017, p. 242.
} 
Presidencia del Congreso hasta que el candidato a la Presidencia del Gobierno no obtuvo los apoyos necesarios ${ }^{38}$, permitiendo así una difícil situación de Gobierno en funciones de manera indefinida, sin que comenzara a correr, como se ha dicho antes, el plazo de dos meses para la disolución de las Cámaras en el caso de no investirse un Presidente en este tiempo fijado en el artículo 99 CE.

Para evitar este problema ${ }^{39}$, casi todas las Comunidades Autónomas no han dejado libertad al Presidente de sus respectivos Parlamentos para convocar esa sesión de investidura, sino que imponen la convocatoria en un plazo determinado ${ }^{40}$ por el Reglamento de la Cámara o la consulta con otros órganos de la Cámara, que van desde los treinta días previstos desde la constitución del Parlamento en Galicia, hasta los diez días en las Comunidades de Aragón, Canarias, Cataluña, Comunidad Foral de Navarra, Principado de Asturias y Región de Murcia. En Cantabria el plazo es de veinte días, mientras que en Andalucía, Castilla y León, Castilla-La Mancha, Comunidad de Madrid, Extremadura e Islas Baleares es de quince días. En estos últimos casos no se especifica si son días hábiles o naturales, "por lo que se ha de entender, como es habitual en Derecho Parlamentario, que sean días hábiles, lo que, obviamente, supone una cierta ampliación de plazo" ${ }^{41}$.

\footnotetext{
${ }^{38}$ Cabría hacer un análisis de la falta de independencia del Presidente del Congreso de los Diputados, que, en muchas ocasiones, es la extensión del Ejecutivo en el Congreso, causa por la cual se tardó tanto en convocar la sesión de investidura. ARAGÓN REYES mantiene que "una condición para que el Presidente del Congreso desempeñase ese papel fundamental es que este cargo lo ocupe por una persona respetada por todos los grupos de la Cámara, caracterizada por su solvencia, neutralidad y no sometimiento a las instrucciones de partidos". ARAGÓN REYES, M., "Legislatura fallida e investidura convulsa. Análisis y consecuencias", op.cit., p. 23.

${ }^{39}$ Es cierto que la disolución de las Cámaras en caso de no investirse a un candidato como Presidente se entiende como un problema, pero, como razona BALAGUER CALLEJÓN, hay que recordar que esta previsión es una apelación al pueblo, "un mecanismo de democracia directa en la medida en que rompe con el principio de representación para permitir que el pueblo se manifieste directamente con la finalidad última de restaurar el principio de representación”. Es, así, una llamada al pueblo "para que decida ante un grave conflicto político, que los grupos políticos por sí mismos no pueden resolver”. BALAGUER CALLEJÓN, M.L., "Derecho de disolución e investidura automática en las Comunidades Autónomas", op. cit., p. 269.

${ }^{40}$ SOLOZÁBAL ECHAVARRÍA mantiene que esta previsión sobre los plazos no sobraría al respecto en la propia Constitución española en la investidura del Presidente del Gobierno. SOLOZÁBAL ECHAVARRÍA, J.J., "La problemática constitucional de la formación del Gobierno y la intervención del monarca en nuestro régimen parlamentario”, op. cit., p. 51.

${ }^{41}$ ÁLVAREZ VÉLEZ, M.I., op. cit., p. 21.
} 
Por último, como se señalaba anteriormente, hay dos Comunidades Autónomas que prevén, actualmente (como hacía antes Navarra), la investidura automática en el caso de que en dos meses no se hubiera obtenido la investidura de la Asamblea: Andalucía y Castilla-La Mancha.

El artículo 14.5 del Estatuto de Autonomía de Castilla-La Mancha regula el procedimiento extraordinario de elección del Presidente de la misma forma que lo hacía la LORAFNA, cuyo procedimiento se ha examinado anteriormente, por lo que no es preciso detenerse en este caso. En el plazo de dos meses sin que se hubiera investido a ningún Presidente, “quedará automáticamente designado el candidato del partido que tenga mayor número de escaños”.

Más problemático es el caso de Andalucía, ya que existe una contradicción clara entre dos regulaciones: de un lado, el tenor literal del artículo 118.3 del Estatuto de Autonomía, que prevé la disolución automática del Parlamento en caso de que ningún candidato obtuviera su confianza en el plazo de dos meses; de otro, el artículo 138.7 del Reglamento del Parlamento, que dispone la investidura automática del candidato del partido con mayor número de escaños una vez transcurrido dicho plazo. Por tanto, teniendo en cuenta que el Estatuto es la norma institucional básica de la Comunidad Autónoma y forma parte del bloque de constitucionalidad, aquí el Reglamento debería ser reformado para adecuarlo al Estatuto.

Para autores como PÉREZ ROYO, estas previsiones de designación automática de los Presidentes "es de constitucionalidad más que dudosa, por no decir de una inconstitucionalidad manifiesta, ya que el supuesto que se contempla es el de la investidura de un candidato que no alcanza la mayoría relativa, es decir, un candidato contra el que se pronuncia expresamente la mayoría de la Cámara”42. Sin embargo, cuando el Tribunal Constitucional ha tenido la oportunidad de posicionarse a este respecto, ha mantenido la constitucionalidad de la norma, como ha ocurrido con las sentencias que han analizado el procedimiento que estaba previsto en la LORAFNA y a las que ya se ha hecho referencia.

\footnotetext{
${ }^{42}$ PÉREZ ROYO, J., "Reflexiones sobre la contribución de la jurisprudencia constitucional a la construcción del Estado autonómico”, en Revista de Estudios Políticos, n 49, 1986, p. 16.
} 


\section{III.- PRIMARIAS Y AFECCIÓN A LA INVESTIDURA EN LAS COMUNIDADES AUTÓNOMAS}

En las páginas precedentes se ha hecho un análisis sobre el sistema institucional de las Comunidades Autónomas, el cual podría traer como resultado una forma de gobierno parlamentaria. Sin embargo, esta afirmación no es compartida por toda la doctrina y los entes autonómicos cuentan con rasgos diferenciadores que podrían poner en duda dicha aserción.

MORTATI define la forma de gobierno como "el modo en que se distribuyen y organizan las distintas funciones del Estado entre los diversos órganos constitucionales"43. GOMES CANOTILHO la define como "la recíproca posición jurídico constitucional de los órganos de soberanía y de sus respectivas conexiones e interdependencias políticas, institucionales y funcionales” ${ }^{44}$, mientras que DE VERGOTTINI habla “del modo en que la titularidad y el ejercicio de las funciones soberanas se reparte entre los órganos constitucionales”45. Según PUNSET BLANCO, "la expresión forma de gobierno es utilizada por la doctrina para aludir a la relación existente entre los órganos superiores del Estado y, en concreto, entre los denominados órganos constitucionales” ${ }^{46}$, o, en este caso, entre los órganos de autogobierno de las Comunidades Autónomas. Según este mismo autor, la forma parlamentaria de gobierno se basa en que "el órgano al que la Constitución confiere el ejercicio de la función ejecutiva en sentido formal -el Gobierno- es designado por el órgano al que la Constitución confiere el ejercicio de la función legislativa en sentido formal (...), estableciéndose así una relación fiduciaria permanentemente verificable”47. Ya se ha analizado cómo todas las Comunidades Autónomas optaron por el parlamentarismo racionalizado, al igual que en el Estado, aunque con algunas diferencias en aquellas donde están presentes fórmulas de parlamentarismo negativo.

\footnotetext{
${ }^{43}$ MORTATI, C., Le forme di Governo, Padova, 1973, p. 3.

${ }^{44}$ GOMES CANOTILHO, J.J., Direito Constitucional e Teoría da Constitução, Coimbra, 2003, p. 573.

${ }^{45}$ DE VERGOTTINI, G., Diritto Constitutionale Comparato, Padova, 1993, pp. 104-105.

${ }^{46}$ PUNSET BLANCO, R., "Forma de gobierno del Estado y forma de gobierno regional. Apuntes para un estudio”, en Revista de la Facultad de Derecho de la Universidad Complutense, nº4, 1981, p. 81.

${ }^{47}$ PUNSET BLANCO, R., op. cit., p. 88.
} 
Gran parte de la doctrina considera que el Presidente del Gobierno en España tiene una situación clara de preeminencia respecto al legislativo ${ }^{48}$, por lo que habría que observar esta característica para analizar de manera correcta nuestra forma de gobierno. Así, BASTID analiza que el criterio más firme para analizar dicha cuestión es la articulación dinámica del marco institucional en los avatares de la vida política ${ }^{49}$. Por tanto, aunque el Parlamento debiera ser el centro de la actividad política dentro de un sistema de estas características, lo cierto es que el Presidente es el protagonista diario debido a su posición institucional, hasta tal punto que ARAGÓN REYES ha calificado esta forma de gobierno como "parlamentarismo presidencial” o "parlamentarismo presidencialista” ${ }^{50}$.

Si la situación predominante del Presidente del Gobierno de España es tal, que ni siquiera representa al Estado ni a la nación, competencia reservada al Rey, ello se acentúa en el caso de las Comunidades Autónomas, dado que "la doble condición del Presidente de la Comunidad Autónoma como representante supremo de la misma y directo del Consejo ejecutivo acentúa efectivamente el locus central que tiene esta figura en la organización institucional autonómica” ${ }^{51}$. Esta preponderancia del Presidente no lo es sólo como órgano unipersonal, sino que el Poder Ejecutivo se encuentra muy por encima del Poder Legislativo, de tal modo que algunos autores han llegado a calificar a los sistemas autonómicos como semipresidenciales. En este sentido, SOLÉ TURA prefirió usar esta categoría y no la de régimen de primer ministro "para subrayar el hecho peculiar de que el sistema general de las Comunidades Autónomas equivale al de un conjunto de sistemas republicanos en el seno de una monarquía parlamentaria, en la medida en que los Presidentes de las Comunidades Autónomas reúnen la doble condición de Presidentes del Gobierno y Presidentes de la

\footnotetext{
${ }^{48}$ ARAGÓN REYES, M., Estudios de Derecho Constitucional, op. cit., p. 497.

${ }^{49}$ BASTID, P., Le gouvernement d'Assamblée, Cujas, París, 1956, p. 390.

${ }^{50}$ ARAGÓN REYES, M., “¿Un parlamentarismo presidencialista?, en Claves de Razón Práctica, no 123 , 2002, p. 49. En el artículo "Legislatura fallida e investidura convulsa. Análisis y consecuencias”, op. cit., p. 30, el mismo autor sostiene que nuestro régimen es un sistema parlamentario presidencialista, una "grave alteración del régimen parlamentario, pues, como consecuencia de esa transformación fáctica, nuestro presidente disfrutaría, incluso, de más poderes que el jefe de Estado de una república presidencialista, pero con menos controles".

${ }^{51}$ REVENGA SÁNCHEZ, M., "Notas sobre el procedimiento de designación del Presidente del órgano colegiado ejecutivo en las Comunidades Autónomas” op. cit., p. 90.
} 
Comunidad”52. No resulta sorprendente la calificación del anterior autor si tenemos en cuenta que la integración de funciones de gobierno junto con funciones de representación puede llegar a chocar de alguna manera con esta forma parlamentaria de gobierno, donde "la separación entre órganos con funciones de gobierno y funciones de representación parece ser consustancial al sistema” ${ }^{33}$; o, a mayor abundamiento, si la forma de gobierno responde a la pregunta de quién manda u ostenta la dirección política $^{54}$. De la misma manera, VIDAL MARÍN mantiene que si se tiene en consideración el funcionamiento en la práctica de los sistemas electorales y de los sistemas de partidos autonómicos, "no podemos sino llegar a la conclusión que la precitada forma de Gobierno parlamentaria aparece contaminada con ciertos y claros tintes presidencialistas"

En cualquier caso, hay que precisar que "la función de máxima representación de la Comunidad tiene un carácter marcadamente simbólico, por cuanto que no atribuye al Presidente auténticos poderes de decisión, ni se traduce en demasiados actos jurídicos” ${ }^{56}$ y que su papel no puede equipararse al del Rey en tanto en cuanto no tiene atribuidas funciones de carácter arbitral y moderador ${ }^{57}$.

Ahondando en lo antepuesto, como indica TUDELA ARANDA, es preciso analizar la función del control de los Parlamentos para saber en qué situación se encuentra respecto al Ejecutivo. Pues bien, “es en relación con la función de control en la que la erosión de la autonomía parlamentaria se hace manifiesta. Y es en relación con la función de control, donde se hace más manifiesta la debilidad material del Parlamento, el desequilibrio lacerante con el Ejecutivo"58. A mayor abundamiento, "los gobiernos suelen estar en disposición de controlar la agenda parlamentaria en relación

${ }^{52}$ SOLÉ TURA, J., op. cit., p. 293 y ss. Con el posicionamiento de SOLÉ TURA también coinciden otros autores como BALAGUER CALLEJÓN. Ver BALAGUER CALLEJÓN, M.L., "Derecho de disolución e investidura automática en las Comunidades Autónomas”, op. cit., p. 217.

${ }^{53}$ CORONA FERRERO, J.M., "El Presidente de la Comunidad Autónoma”, en Anuario de Derecho Parlamentario, $\mathrm{n}^{\circ}$ 14, 2003, p. 37.

${ }^{54}$ GARCÍA ROCA, J., "Sobre el autogobierno constitucional en Castilla y León”, en La Constitución de 1978 y las Comunidades Autónomas, CEPC, Madrid, 2003, p. 212.

${ }^{55}$ VIDAL MARÍN, T., op.cit., p. 3.

${ }^{56}$ BIGLINO CAMPOS, P., "El Presidente y la Junta”, en GARCÍA ROCA, J. (coord.). Derecho Público de Castilla y León, Universidad de Valladolid, 1999, p. 166.

${ }^{57}$ Op. cit., p. 167.

${ }^{58}$ TUDELA ARANDA, J., “El Parlamento autonómico y la calidad de la democracia”, op. cit., p. 41. 
con estos instrumentos (de control) a través de los grupos parlamentarios de la mayoría" 59 .

En relación con lo anterior, de otra mano, sí que se pueden encontrar tintes parlamentarios que no se formulan en el ámbito estatal, pero sí en las Comunidades Autónomas. Por ejemplo, la exigencia de que el Presidente sea parlamentario, lo cual “comporta una acentuación del carácter parlamentario del sistema de gobierno”, ${ }^{60}$ que trae como ventaja una mayor legitimidad democrática para el Presidente "otorgada por la propia elección por parte de los ciudadanos del que va a ser candidato a la Presidencia del Gobierno regional”61; pero también tiene inconvenientes, sobre todo para las posibles negociaciones en las crisis de gobierno, ya que impediría nombrar a un Presidente extraparlamentario a través de una moción de censura constructiva ${ }^{62}$.

Teniendo en cuenta todo lo anterior, se parte de la base de que, efectivamente, nuestras Comunidades Autónomas cuentan con una forma de gobierno parlamentaria, dado que el Presidente recibe la confianza del Parlamento para ser designado, y además disponen fórmulas de parlamentarismo racionalizado, como la moción de censura constructiva o la cuestión de confianza. Sin embargo, a su vez, manifiestan rasgos marcadamente presidencialistas, pero no son sistemas presidencialistas como tales porque el jefe de Gobierno, en este caso, no es elegido de manera directa por los ciudadanos. De esta forma, la posible introducción de primarias en los partidos políticos para designar a su candidato a la Presidencia de las Comunidades Autónomas, en tanto en cuanto éste no es elegido de manera directa por el electorado, podría conllevar una contradicción con la forma de gobierno, dado que la confianza la obtiene del Parlamento y no directamente a partir de los ciudadanos; pero también podría ser algo lógico si se tiene en cuenta el funcionamiento, la dinámica, del sistema constitucional en las

\footnotetext{
${ }^{59}$ TUDELA ARANDA, J., “La renovación de la función parlamentaria de control”, en Teoría y Realidad Constitucional, $\mathrm{n}^{\circ}$ 19, 2007, p. 98.

${ }^{60}$ BASTIDA FREIJEDO, F.J., "De nuevo sobre el modo de designación de los Presidentes Autonómicos y la forma de gobierno”, op. cit., p. 45.

${ }^{61}$ VIDAL MARÍN, T., op. cit., p. 6.

${ }^{62}$ BASTIDA FREIJEDO, F.J., "De nuevo sobre el modo de designación de los Presidentes Autonómicos y la forma de gobierno”, op. cit., p. 44. Esto sucedería, por ejemplo, en el caso de Pedro Sánchez, Secretario General del PSOE, si en el ámbito estatal también existiese dicha exigencia.
} 
Comunidades Autónomas, que es la clave para determinar su forma de gobierno ${ }^{63}$. Por tanto, se trata de analizar aquí si la posible introducción de primarias en los partidos enfatizaría en los rasgos presidencialistas de la forma de gobierno de las Comunidades Autónomas y, en segundo lugar, si dicha modificación es viable.

Es opinión unánime en la doctrina que los partidos políticos protagonizan la democracia contemporánea y que dicha influencia, incluso, "no se limita al momento electoral, sino que se extiende también al ejercicio, por parte de los ciudadanos, de las otras formas de participación que completan la representación”64. A mayor abundamiento, para SÁNCHEZ MUÑOZ, “si en el parlamentarismo liberal la representación se concebía como una relación entre representante y representados, en la democracia de partidos se concibe como una relación en la que el partido se sitúa como intermediario entre ambos”65 y "dentro de los partidos no hay ninguna posibilidad de ser candidato sin el placet de la dirección del partido. De hecho, los parlamentarios son escogidos por los partidos, que los someten a la ratificación del electorado”66 . Hasta tal punto se podría considerar lo anterior que autores como GARRORENA MORALES han llegado a afirmar que la verdadera representación no lo es entre representante y representado, sino entre partido y elector, aunque los textos constitucionales no se atrevan a decirlo ${ }^{67}$.

Teniendo en cuenta lo anterior y el carácter que atribuye el artículo 6 CE a dichas fuerzas como instrumentos fundamentales para la participación política, son sumamente preocupantes los datos que conocemos habitualmente según los cuales los partidos no son asociaciones que inspiren confianza hacia la ciudadanía. Así, “en los últimos años las opiniones respecto a los partidos políticos han cambiado, reduciéndose el número de ciudadanos que tienen actitudes positivas, al menos en abstracto, sobre

\footnotetext{
${ }^{63}$ MARTín DE LA VEGA, A., "Forma de gobierno y medidas de mejora de la calidad democrática en la Comunidad de Castilla y León”, en Revista Jurídica de Castilla y León, no 42, 2017, p 38.

${ }^{64}$ BIGLINO CAMPOS, P., “Conclusiones y propuestas”, en BIGLINO CAMPOS, P. (coord.): Partidos políticos y mediaciones de la democracia directa, CEPC, Madrid, 2016, p. 392.

${ }^{65}$ SÁNCHEZ MUÑOZ, O., "Los partidos y la actual crisis de representatividad del parlamento", en CASCAJO DE CASTRO, J.L. y MARTÍN DE LA VEGA, A. (coords.), Participación, representación y democracia, Tirant lo Blanch, Valencia, 2016, p. 345.

${ }^{66}$ Op. cit, p. 349.

${ }^{67}$ GARRORENA MORALES, A., Representación política y Constitución democrática, Cuadernos Civitas, Madrid, 1991, p. 67.
} 
ellos (...). Sólo el 50 por ciento dice que son instrumentos que permiten la participación ciudadana” ${ }^{68}$.

Por este motivo y otros, como la falta de incentivos reales para la participación $^{69}$, es lógico que en el momento actual se estén proponiendo fórmulas para introducir por vía legislativa que regeneren la vida interna de los partidos políticos a través de instrumentos como las primarias, dado que, además, “la regulación jurídica del partido es una garantía imprescindible para asegurar la participación popular en la actuación del Estado”70.

Es necesario un desarrollo del artículo 6 CE. El legislador, en este sentido, tiene un amplio margen, pero ha optado por establecer una legislación de mínimos en la Ley Orgánica 6/2002, de 27 de junio, de partidos políticos. Lo anterior ha de ponerse en relación con el derecho de autoorganización de los partidos, ya que los partidos políticos "no dejan de ser asociaciones privadas, a consecuencia de lo cual caen bajo la protección del derecho de asociación, regulado en el artículo 22 CE”71. Sin embargo, debido a su relevancia constitucional, encuentran ciertos límites a su capacidad de autoorganización, en concreto, que su estructura y funcionamiento interno han de ser democráticos, como estipula el mismo artículo $6 \mathrm{CE}$, a lo que hay que sumar que "el significado constitucional del mandato de democracia interna se realiza precisamente a través de las mayores garantías de participación en su seno”72.

El Tribunal Constitucional, en su sentencia 56/1995, ha dictaminado que el derecho de autoorganización del partido “tiende, precisamente, a preservar la existencia

\footnotetext{
${ }^{68}$ OÑATE RUBALCABA, P., "La representación política en España: las perspectivas de los ciudadanos y de los diputados", en LLERA RAMO, F. J. (coord.), Desafección política y regeneración democrática en la España actual: diagnósticos y propuestas, CEPC, Madrid, 2016, p. 122.

${ }^{69}$ ROURA ÁRBORE, S., "Notas para una política de reforma del Gobierno Local”, en Anuario da Facultade de Dereito da Universidade da Coruña, nº 8, 2004, p. 1154.

${ }_{70}$ SOLOZÁBAL ECHAVARRÍA, J.J., "Sobre la constitucionalización de los partidos políticos en el Derecho Constitucional y en el ordenamiento español”, en Revista de Estudios Políticos, no 45, mayojunio 1985, p. 157.

${ }^{71}$ GIMÉNEZ GLUCK, D., "El derecho de asociación de los partidos políticos y la regulación legal de las elecciones primarias”, en Revista Española de Derecho Constitucional, ${ }^{\circ}$ 102, septiembre-diciembre 2014, p. 213.

${ }^{72}$ ALGUACIL GONZÁLEZ-AURIOLES, J., "Incidencia de los resultados electorales sobre el pluralismo político y la democracia interna de los partidos”, en Revista Española de Derecho Constitucional, nº 109, 2017, p. 268.
} 
de un ámbito libre de interferencias de los poderes públicos en la organización y funcionamiento interno de los partidos” (F.J. $3^{\circ}$ ). En dicha sentencia se discute si los afiliados a un partido tienen derecho a que éste posea una organización territorial descentralizada. El Alto Tribunal llega a la conclusión de que dicho derecho sería “de rango exclusivamente estatutario no integrado en el contenido del derecho fundamental de asociación”.

Desde luego, no es discutible que se han de favorecer las estructuras de participación interna en los partidos políticos para evitar que la mayoría impida manifestarse a las corrientes minoritarias. Lo anterior puede llevar a ser un fortalecimiento para la propia organización, pero también puede causar contradicciones en el sentido de que puede llegar a colisionar con los fines del partido, que son el triunfo electoral $^{73}$, como se ha puesto de manifiesto recientemente en los debates que han tenido lugar en partidos como Podemos y el PSOE con la pugna de liderazgos.

Precisamente el peligro de las primarias está “en reducir la política (...) a una batalla por el liderazgo" ${ }^{74}$, pero no es menos cierto que ello serviría "para reflejar en las candidaturas las diversas sensibilidades existentes en el seno de la organización” ${ }^{75}$. La posibilidad de introducir vía legislativa las primarias en los partidos políticos es una cuestión discutida en la doctrina, en la que nos encontramos diversas opiniones. El legislador ha de encontrar un equilibrio "entre los ámbitos individual y colectivo y garantizar unos mínimos de pluralismo en el interior de los partidos”76. Para SAIZ ARNAIZ, “el juego combinado de los artículos 6 y 23.1 de nuestra Norma fundamental obliga a entender que la exigencia constitucional de democracia interna se concreta, también, en el derecho de participación de los afiliados en la designación de quienes

\footnotetext{
${ }^{73}$ AGUACIL GONZÁLEZ-AURIOLES, J., op. cit., p. 272.

74 GARCÍA SANTSMASES, A., "Encuesta sobre la regulación jurídica de los partidos políticos”, en Teoría y Realidad Constitucional, $\mathrm{n}^{\circ}$ 6, $2^{\circ}$ semestre 2000, p. 27.

${ }^{75}$ MURILLO DE LA CUEVA, P.L., “Encuesta sobre la regulación jurídica de los partidos políticos”, op. cit., p. 30.

76 SALAZAR BENÍTEZ, O., "Las primarias socialistas: una experiencia de democratización de la selección de candidatos”, en Teoría y Realidad Constitucional, nº 6, $2^{\circ}$ semestre 2000, p. 161.
} 
habrán de integrar las listas electorales de los partidos políticos”77, pero alcanzar el fin constitucional de garantizar el carácter democrático de la elaboración de las candidaturas puede alcanzarse "sin intervenir de modo tan restrictivo sobre la libertad asociativa" $^{78}$.

Sin embargo, siguiendo a PÉREZ-MONEO, la importancia de la selección del candidato, con consecuencias internas y externas para los partidos, induce a pensar que dicho proceso “debería venir regulado por ley" ${ }^{79}$. Asimismo, hay que tener en cuenta que si dicha “configuración legal es demasiado exhaustiva puede suponer una interferencia ilegítima en la libertad de los partidos de autoorganizarse, pero si es demasiado parca, la prevalencia incondicionada del derecho de autoorganización puede suponer un perjuicio de los derechos de los afiliados” ${ }^{80}$. Por este motivo, el legislador deberá ponderar su intervención y diferenciar las primarias, entre abiertas y cerradas. Así, "la repercusión que la nominación de candidatos tiene, pues, en la futura composición del Parlamento y, por lo tanto, en el propio funcionamiento de la representación, justifica un grado mayor de intervención pública”81. Las primarias abiertas “al transferir una decisión capital del partido al conjunto de la ciudadanía, suponen una renuncia tan importante a la autoorganización asociativa que una imposición legal de las mismas seguramente implicaría una afectación inconstitucional del derecho de asociación del artículo 22 CE”, ${ }^{82}$, aunque haya autores que piensen lo contrario $^{83}$, pero no ocurriría lo mismo con las primarias cerradas. A mayor abundamiento, “para salvaguardar el interés general, el Estado tiene derecho y el deber

\footnotetext{
${ }^{77}$ SAIZ ARNAIZ, A., "Elecciones primarias, representación política y democracia interna en los partidos: entre la ilusión y el escepticismo”, en Anuario de Derecho Constitucional y Parlamentario, no 12-13, 2000-2001, p. 187.

${ }^{78}$ SAIZ ARNAIZ, A., op. cit., p. 191.

${ }^{79}$ PÉREZ-MONEO, M., La selección de candidatos electorales en los partidos, CEPC, Madrid, 2012, pp. 175-176

${ }^{80}$ GUTIÉRREZ GUTIÉRREZ, I., "Democracia en los partidos y derechos de los afiliados (nota sobre la STC 56/1995)" en ANSENSI SABATER, J. (coord.): Ciudadanos e instituciones en el constitucionalismo actual, Tirant lo Blanch, Valencia, 1997, p. 360.

${ }^{81}$ BIGLINO CAMPOS, P., "Intervención del legislador y selección de candidatos por los partidos políticos: una perspectiva comparada”, en Teoría y Realidad Constitucional, n 35, 2015, p. 215.

${ }^{82}$ GIMÉNEZ GLUCK, D., op. cit., p. 219.

${ }^{83}$ Como indica GIMÉNEZ GLUCK, D. en op. cit., nota 24: ESPÍN TEMPLADO, E., "Representación política y partidos políticos. Derecho de sufragio y régimen electoral”, en GARCÍA DE ENTERRÍA, E. y ClAVERO ARÉVAlO, M. (dir.), El Derecho Público de finales de siglo (una perspectiva iberoamericana), Congreso de los Diputados, Madrid, 1994, p. 131.
} 
de intervenir en la fase electoral preparatoria de la misma manera que en la fase final, de prestar su ayuda para formular tanto el análisis como la síntesis de las opiniones electorales" ${ }^{84}$.

La posibilidad de regular las primarias en los partidos políticos afecta, al menos, a dos derechos fundamentales: el de asociación (artículo $22 \mathrm{CE}$ ) y el de participación (artículo $23 \mathrm{CE}$ ). Por tanto, no parece claro que las Comunidades Autónomas tengan competencia para legislar sobre dicha cuestión, ya que correspondería al legislador orgánico, pero tampoco se puede descartar, ya que también entra en juego su competencia en la organización de sus instituciones de autogobierno (artículo 148.1.1 ${ }^{\text {a }}$ $\mathrm{CE}$ ). De esta manera, hay que tener en cuenta que las Autonomías podrían regular dicho aspecto en caso de "poseer un título competencial que las habilite para llevar a cabo la actuación de que se trate»" ${ }^{85}$ y que "la regulación de los aspectos no esenciales del derecho puede corresponder también a las Comunidades Autónomas, siempre que el legislador autonómico disponga de competencias sectoriales sobre la materia” ${ }^{\text {}}$. Así, en iniciativas como la Proposición de Ley para la reforma de la Ley 3/1987, de 30 de marzo, Electoral de Castilla y León, presentada por el Grupo Parlamentario Ciudadanos $^{87}$, en la que se incluye dicha eventualidad, cabría la duda sobre su posible constitucionalidad, como así lo han manifestado los servicios jurídicos de las propias Cortes de Castilla y León (precisamente, entre otras razones, al considerar que es materia reservada al legislador orgánico), pero también habría que tener en cuenta la capacidad de autogobierno y las competencias en la materia de la Comunidad para resolver si dicha regulación sería o no conforme a la Constitución.

De la misma manera, como se ha mencionado antes, la forma parlamentaria de gobierno se basa en una relación fiduciaria entre el Parlamento y el Ejecutivo, en concreto, el Presidente del mismo. La inclinación presidencialista de este modelo en el ámbito autonómico es mayor que en el estatal por los motivos ya expresados y, en todo

\footnotetext{
${ }^{84}$ OSTROGORSKI, M., La democracia y los partidos políticos, Trotta, Madrid, 2008, pp. 100-101.

${ }^{85}$ BIGLINO CAMPOS, P., "Reforma de los Estatutos de Autonomía y distribución de competencias”, en Revista Jurídica de Castilla y León, $\mathrm{n}^{\circ}$ monográfico dedicado a La Reforma de los Estatutos de Autonomía, 2005, p. 249.

${ }^{86}$ Op. cit., p. 251.

${ }^{87}$ Boletín Oficial de las Cortes de Castilla y León, n ${ }^{\text {85, }} 19$ de febrero de 2016, pp. 11121 y ss.
} 
caso, la posibilidad de que se obligara a los partidos políticos a elegir a su candidato a la Presidencia por primarias podría introducir una nueva relación fiduciaria entre dicho candidato y quienes lo hubieran elegido a través de este sistema (ya sean únicamente militantes del partido o también simpatizantes en caso de que se abrieran) y cabría preguntarse si dicha elección sería vinculante para el Grupo Parlamentario o la Presidencia de la Cámara a la hora de designar, posteriormente, a los candidatos a la Presidencia que se sometan a investidura en sesión plenaria. Por tanto, la introducción de las primarias enfatizaría el "parlamentarismo presidencialista” y podría llegar a transformar la forma de gobierno de las Comunidades Autónomas.

SOLÉ TURA ya defendió que la elección del Presidente de las Comunidades Autónomas era una “elección prácticamente directa” y que "desde el punto de vista político, las elecciones en las Comunidades Autónomas son unas elecciones presidenciales”, hasta el punto de que "el papel político de los Diputados que deben elegir al Presidente equivale al de unos compromisarios, es decir, al de unos electores con voto comprometido de antemano” ${ }^{88}$, pero lo mismo ocurre en el ámbito estatal y no por eso estamos ante un modelo semipresidencial y el nuevo escenario partidista ha demostrado que los Parlamentos tienen mucha mayor relevancia actualmente en la investidura del Presidente.

\section{IV.- CONCLUSIONES}

1.- La mayoría de Comunidades Autónomas han tomado como referencia el artículo 99 CE para investir a su Presidente. Sin embargo, existen diferencias entre ellas y entre el Estado, como las que usan fórmulas de parlamentarismo negativo, establecen un voto nominal a partir de una pluralidad de candidatos propuestos por los Grupos Parlamentarios o diputados o aquellas que disponen un plazo para celebrar la sesión de investidura. Éstas pueden ser beneficiosas para, en primer lugar, garantizar la investidura de un Presidente y, por tanto, la formación de un Gobierno. Como inconveniente, éste puede ser sumamente débil. En segundo lugar, el establecimiento de un plazo para la celebración de la sesión de investidura permitiría una mayor definición temporal de un Gobierno en funciones y una mayor autonomía parlamentaria, por lo que

${ }^{88}$ SOLÉ TURA, J., op. cit., pp. 298-299. 
sería conveniente estudiar su incorporación también en el ámbito estatal y en aquellas Comunidades Autónomas donde no está regulado.

2.- En aquellas Comunidades Autónomas donde no existe plazo para convocar la sesión de investidura, así como en el Estado, se podría explorar, además de la anterior opción, establecer en el Reglamento de sus respectivas Asambleas un mecanismo de exigencia de responsabilidad política del Presidente del Parlamento, debido a la relación fiduciaria que existe entre éste y la propia Asamblea, que fue quien lo eligió. Aunque en el ámbito estatal no exista tampoco ningún mecanismo de responsabilidad política del Presidente del Congreso o del Senado, ello no obsta para que se pueda desarrollar debido a la relación de confianza que existe entre los diputados y éste y como medida de garantía del cumplimiento de sus funciones.

3.- No parece que sea posible la regulación por parte del legislador autonómico de las primarias en los partidos políticos de manera general, dado que es una materia reservada al legislador orgánico, como se ha señalado. En todo caso, el legislador autonómico sí que podría explorar la posibilidad de regular en sus leyes electorales cómo han de proceder los partidos políticos en el caso de que éstos se decidan a realizar primarias en su seno, pero nunca sin imponerlo de manera obligatoria, en virtud del artículo 148.1.1 $1^{\mathrm{a}} \mathrm{CE}$.

4.- La crisis de los partidos políticos requiere de medidas para que puedan recuperar la falta de confianza perdida. Una de ellas es el fomento de la participación, como son las primarias en los partidos políticos, pero no la única. Del análisis realizado se extrae que, aunque las Comunidades Autónomas cuenten con una forma de gobierno parlamentaria, también tienen fuertes sesgos presidencialistas, por lo que no parece deseable introducir medidas legislativas encaminadas a fortalecer esto último, sino más bien a robustecer el Parlamento. La posible introducción de primarias en los partidos políticos vendría, más bien, a enfatizar lo primero, dado que se establecería una nueva relación fiduciaria entre el candidato y sus electores en las primarias, fomentándose las notas del presidencialismo dentro de un sistema parlamentario. Asimismo, no queda clara cuál es la viabilidad de dicha vinculación en tanto en cuento es el Parlamento el último en designar al Presidente. Teniendo en cuenta esto y que, además, el nuevo 
escenario partidista deja Parlamentos mucho más fraccionados, es posible que los partidos políticos necesiten llegar a acuerdos de investidura y que una decisión tomada en primarias reduciría de forma muy notable su margen de maniobra. Es más, podría llegarse al caso de que dicha decisión no fuera vinculante y la decisión tomada por los electores en primarias a la hora de designar a un candidato a la Presidencia no fuera seguida por el partido en función de tales negociaciones para conformar un Gobierno, lo que podría ahondar aún más en la crisis de credibilidad de los propios partidos. Además de lo anterior, es de dudosa constitucionalidad que esta decisión pudiese vincular a los Grupos Parlamentarios y/o a los Presidentes de los Parlamentos en el momento de propuesta del futuro candidato.

Por tanto, aunque sean beneficiosas las medidas de participación que se puedan introducir en los partidos políticos legislativamente, concluyo que hay otras posibilidades que pueden llevar a fortalecerlos, como son la limitación de mandatos, las incompatibilidades orgánicas o el reconocimiento y regulación en sus estatutos de corrientes internas. En todo caso, si se decidiera el legislador a regular las primarias, ha de dejar claro que dicha decisión no podría vincular posteriormente al Parlamento ni a ningún otro actor que intervenga en la investidura del Presidente, ya sea autonómico o de la Nación, porque ello significaría modificar la forma de gobierno parlamentaria imperante no sólo en el ámbito autonómico, sino también en el estatal, y destacar los rasgos presidencialistas de la misma sin ningún contrapeso o control a cambio.

\section{V.- BIBLIOGRAFÍA}

ALGUACIL GONZÁLEZ-AURIOLES, J., "Incidencia de los resultados electorales sobre el pluralismo político y la democracia interna de los partidos”, en Revista Española de Derecho Constitucional, nº 109.

ÁLVAREZ VÉLEZ, M. I., "La investidura del Presidente del Gobierno y las similitudes y diferencias de las investiduras de los Presidentes Ejecutivos autonómicos”, en Revista General de Derecho Constitucional, n 22, 2016.

ALZAGA VILLAAMIL. O., Comentario sistemático a la Constitución española de 1978, Marcial Pons, $2^{\text {a }}$ ed., Madrid, 2016. 
ARAGÓN REYES, M., “¿Un parlamentarismo presidencialista?, en Claves de Razón Práctica, nº 123, 2002.

Estudios de Derecho Constitucional, CEPC, $3^{\text {a }}$ edición, Madrid, 2013.

“Legislatura fallida e investidura convulsa. Análisis y consecuencias”, en Revista Española de Derecho Constitucional, nº 109, 2017.

BALAGUER CALLEJÓN, M.L., "Derecho de disolución e investidura automática en las Comunidades Autónomas”, en Revista de las Cortes Generales, nº 18, 1989.

BASTID, P., Le gouvernement d’Assamblée, Cujas, París, 1956.

BASTIDA FREIJEDO, F.J., "Investidura de los Presidentes Autonómicos y parlamentarismo negativo”, en Revista Jurídica de Asturias, nº 17, 1993.

"De nuevo sobre el modo de designación de los Presidentes Autonómicos y la forma de gobierno”, en Parlamento y Constitución. Anuario de las Cortes de CastillaLa Mancha, nº 5, 2001.

BIGLINO CAMPOS, P., “Conclusiones y propuestas”, en BIGLINO CAMPOS, P. (coord.), Partidos políticos y mediaciones de la democracia directa, CEPC, Madrid, 2016.

“Intervención del legislador y selección de candidatos por los partidos políticos: una perspectiva comparada”, en Teoría y Realidad Constitucional, nº 35, 2015.

“Reforma de los Estatutos de Autonomía y distribución de competencias”, en Revista Jurídica de Castilla y León, $\mathrm{n}^{\circ}$ monográfico dedicado a La Reforma de los Estatutos de Autonomía, 2005.

“El Presidente y la Junta”, en GARCÍA ROCA, J. (coord.), Derecho Público de Castilla y León, Universidad de Valladolid, 1999.

CORONA FERRERO, J.M., "El Presidente de la Comunidad Autónoma”, en Anuario de Derecho Parlamentario, no 14, 2003.

DE VERGOTTINI, G., Diritto Constitutionale Comparato, Padova, 1993. 
DELGADO RAMOS, D., "Breves notas sobre una cuestión controvertida: ¿es posible acortar los plazos para la investidura del candidato a Presidente del Gobierno?”, en Asamblea: revista parlamentaria de la Asamblea de Madrid, nº 26, 2012.

DURÁN ALBA, J. F., "Las instituciones de autogobierno y otros órganos autonómicos ante el proceso de reforma estatutaria”, en La Reforma de los Estatutos de Autonomía, Junta de Castilla y León-Revista Jurídica de Castilla y León, 2005.

“El cierre del sistema institucional castellano y leonés tras la última reforma estatutaria: semejanzas y diferencias con el modelo estatal”, en Revista Jurídica de Castilla y León, $\mathrm{n}^{\circ}$ extra 1, 2004.

ESPÍN TEMPLADO, E., “Representación política y partidos políticos. Derecho de sufragio y régimen electoral”, en GARCÍA DE ENTERRÍA, E. y CLAVERO ARÉVAlO, M. (dir.), El Derecho Público de finales de siglo (una perspectiva iberoamericana), Congreso de los Diputados, Madrid, 1994.

GARCÍA ROCA, J., “Sobre el autogobierno constitucional en Castilla y León”, en La Constitución de 1978 y las Comunidades Autónomas, CEPC, Madrid, 2003.

GARCÍA SANTSMASES, A., "Encuesta sobre la regulación jurídica de los partidos políticos”, en Teoría y Realidad Constitucional, nº 6, $2^{\circ}$ semestre 2000.

GARRORENA MORALES, A., Representación política y Constitución democrática, Cuadernos Civitas, Madrid, 1991.

GIMÉNEZ GLUCK, D., “El derecho de asociación de los partidos políticos y la regulación legal de las elecciones primarias”, en Revista Española de Derecho Constitucional, $\mathrm{n}^{\circ}$ 102, septiembre-diciembre 2014.

GIMÉNEZ SÁNCHEZ, I.M., "La forma de gobierno autonómica tras las recientes reformas de los Estatutos de Autonomía”, en Asamblea: Revista Parlamentaria de la Asamblea de Madrid, núm. 22, junio 2010.

GOMES CANOTILHO, J.J., Direito Constitucional e Teoría da Constitução, Coimbra, 2003. 
GUTIÉRREZ GUTIÉRREZ, I., “Democracia en los partidos y derechos de los afiliados (nota sobre la STC 56/1995)” en ANSENSI SABATER, J. (coord.), Ciudadanos e instituciones en el constitucionalismo actual, Tirant lo Blanch, Valencia, 1997.

MARTÍN DE LA VEGA, A., "Forma de gobierno y medidas de mejora de la calidad democrática en la Comunidad de Castilla y León”, en Revista Jurídica de Castilla y León, $n^{\circ}$ 42, 2017.

MORTATI, C., Le forme di Governo, Padova, 1973.

OÑATE RUBALCABA, P., “La representación política en España: las perspectivas de los ciudadanos y de los diputados”, en LLERA RAMO, F. J. (coord.), Desafección política y regeneración democrática en la España actual: diagnósticos y propuestas, CEPC, Madrid, 2016.

ORTEGA SANTIAGO, C., "Sobre la forma de Gobierno de las Comunidades Autónomas y sus fuentes normativas de ordenación”, en Revista Española de Derecho Constitucional, $\mathrm{n}^{0}$ 59, mayo-agosto 2000.

OSTROGORSKI, M., La democracia y los partidos políticos, Trotta, Madrid, 2008.

PENDÁS GARCÍA, B., “Gobierno y forma de gobierno de las Comunidades Autónomas. Reflexiones sobre el dogma de la homogeneidad y sus límites”, en Documentación Administrativa, nº 215, julio-septiembre 1988.

PÉREZ ROYO, J., "Reflexiones sobre la contribución de la jurisprudencia constitucional a la construcción del Estado autonómico”, en Revista de Estudios Políticos, nº 49, 1986.

PÉREZ-MONEO, M., La selección de candidatos electorales en los partidos, CEPC, Madrid, 2012. 
PUNSET BLANCO, R., "Forma de gobierno del Estado y forma de gobierno regional. Apuntes para un estudio", en Revista de la Facultad de Derecho de la Universidad Complutense, $\mathrm{n}^{\circ} 4,1981$.

RAMÓN FERNÁNDEZ, T., “La organización territorial del Estado y la Administración Pública en la nueva Constitución”, en Lecturas sobre la Constitución española, vol. 1, UNED, Madrid, 1978.

REVENGA SÁNCHEZ, M., “Notas sobre el procedimiento de designación del Presidente del órgano colegiado ejecutivo en las Comunidades Autónomas”, en Revista Vasca de Administración Pública, nº 14, 1986.

ROURA ÁRBORE, S., “Notas para una política de reforma del Gobierno Local”, en Anuario da Facultade de Dereito da Universidade da Coruña, nº 8, 2004.

SAIZ ARNAIZ, A., "Elecciones primarias, representación política y democracia interna en los partidos: entre la ilusión y el escepticismo”, en Anuario de Derecho Constitucional y Parlamentario, nº 12-13, 2000-2001.

SALAZAR BENÍTEZ, O., "Las primarias socialistas: una experiencia de democratización de la selección de candidatos”, en Teoría y Realidad Constitucional, ${ }^{\circ}$ 6, $2^{\circ}$ semestre 2000 .

SÁNCHEZ AGESTA, L, Sistema político de la Constitución española de 1978, EDERSA, Madrid, 1987.

SÁNCHEZ MUÑOZ, O., "El fin (momentáneo) del bipartidismo en España: análisis de los resultados electorales de 2015 y 2016”, en Revista Española de Derecho Constitucional, $\mathrm{n}^{0}$ 109, 2017.

"Los partidos y la actual crisis de representatividad del parlamento", en CASCAJO DE CASTRO, J.L. y MARTÍN DE LA VEGA, A. (coords.), Participación, representación y democracia, Tirant lo Blanch, Valencia, 2016. 
SOLÉ TURA, J., "Las Comunidades Autónomas como sistemas semipresidenciales”, en El Gobierno en la Constitución Española y en los Estatutos de Autonomía, Diputación de Barcelona, 1985.

SOLOZÁBAL ECHAVARRÍA, J.J., "Sobre la constitucionalización de los partidos políticos en el Derecho Constitucional y en el ordenamiento español”, en Revista de Estudios Políticos, nº 45, mayo-junio 1985.

“La problemática constitucional de la formación del Gobierno y la intervención del monarca en nuestro régimen parlamentario”, en Revista Española de Derecho Constitucional, $\mathrm{n}^{\circ}$ 109, 2017.

TORRES DEL MORAL, A., Principios de Derecho Constitucional español, Madrid, 2004.

TUDELA ARANDA, J., “El Parlamento autonómico y la calidad de la democracia”, en TUDELA ARANDA, J. (ed.), Los Parlamentos autonómicos en tiempos de crisis, Fundación Manuel Giménez Abad, Zaragoza, 2015.

“La renovación de la función parlamentaria de control”, en Teoría y Realidad Constitucional, n 19, 2007.

VIDAL MARÍN, T., "La investidura de los Presidentes Autonómicos: la eliminación de la designación automática. ¿Acierto del legislador?”, en Repertorio Aranzadi del Tribunal Constitucional, n 15, 2007.

VINTRÓ CASTELLS, J., La investidura parlamentaria del Gobierno: perspectiva comparada y Constitución española, Congreso de los Diputados, Madrid, 2006. 